\title{
Choice, price and service characteristics in the Irish broadband market
}

\section{Seán Lyons*}

Economic and Social Research Institute,

Institute, Whitaker Square, Sir John Rogerson's Quay,

Dublin 2, Ireland

Fax: +353-1-863-2100

E-mail: sean.lyons@esri.ie

and

Department of Economics,

Trinity College,

Dublin 2, Ireland

*Corresponding author

\section{Michael Savage}

Economic and Social Research Institute,

Institute, Whitaker Square, Sir John Rogerson's Quay,

Dublin 2, Ireland

E-mail: michael.savage@esri.ie

\begin{abstract}
Using detailed plan-level data, this paper examines the choice, price and quality of broadband services available to consumers in Ireland over time. We find modest geographical (county level) variation in broadband services. Hedonic regression analysis is used to value various components of the broadband service. Download and upload speed attract positive valuations, whereas contention ratio is valued negatively as expected. The results suggest that the marginal valuation of download speed decreases as the speed level increases, with little value currently placed upon speeds above about $60 \mathrm{Mb} / \mathrm{s}$.
\end{abstract}

Keywords: broadband services; market analysis; hedonic; Ireland.

Reference to this paper should be made as follows: Lyons, S. and Savage, M. (2013) 'Choice, price and service characteristics in the Irish broadband market', Int. J. Management and Network Economics, Vol. 3, No. 1, pp.1-21.

Biographical notes: Sean Lyons is an Associate Research Professor at the Economic and Social Research Institute and an Adjunct Associate Professor at Trinity College Dublin. He is also Honorary Secretary of the Statistical and Social Inquiry Society of Ireland. Formerly, he was a partner at Indecon Economic Consultants, Dublin; a Senior Adviser in the Office of the Director of Telecommunications Regulation, Dublin; and a Managing Consultant at London Economics, London and Dublin. He holds a PhD in Economics from Trinity College Dublin, an MPhil in Economics from Cambridge and a BA in History from Trinity College Dublin. His specialises in applied microeconomics, with a particular focus on regulation, consumer demand analysis and policy modelling. 
Michael Savage joined the ESRI as a Research Assistant in September 2011. $\mathrm{He}$ is a $\mathrm{PhD}$ candidate in University College Dublin (UCD), where he also completed his MA in Economics. He previously worked as a tutor in UCD and worked in Ulster Bank before returning to university. Before this, he graduated with a BA in Economics, Politics and Law and MA in Development from DCU. His research interests include issues in public finance and public policy. Along with his work in communications economics in the ESRI, Michael works on tax and welfare issues using SWITCH, the ESRI's microsimulation model of the tax and benefit system.

\section{Introduction}

The communications market in Ireland has developed significantly since the introduction of broadband services. The modern communications consumer expects a wide choice of service provider and technology, a high quality of services and also value for money (ComReg, 2010). In this paper, we examine how the structure of the broadband market in Ireland has developed with the increase in choice and competition in the marketplace. Using data from the ComReg tariff comparison website, Callcosts.ie, we try to address a number of questions:

- Are rural counties disadvantaged in the broadband service they receive or the price they pay for it?

- How has the national market for broadband in Ireland developed since 2006 ?

- How much are people currently willing to pay for a faster and better quality broadband service in Ireland?

The benefits of investing in high speed broadband are uncertain. Although the Irish Government has been encouraged to actively pursue a rollout of high speed broadband (Forfás, 2010; DCENR, 2012), other researchers have raised questions about how big an economic contribution is to be expected from high speed services (Kenny and Kenny, 2011; Howell and Grimes, 2010). There is little empirical research on the value that the market places on incremental download speed or other aspects of service quality for existing services, and obviously projecting likely future values of such parameters is even more difficult. In this paper, we use hedonic regressions to estimate the implied marginal value of broadband download speed, as well as several other components of the broadband service. We examine whether the market valuation of an increment to download speed varies as the speed level rises and whether it seems to be rising or falling over time. Although estimates based on historical information cannot give a strong indication of how valuations will develop over the medium term in a market with fast technical progress, they may be helpful with regard to near term demand.

The remainder of the paper is organised as follows. In Section 2, we examine the related literature. Section 3 discusses the data and outlines the hedonic regression approach. Section 4 reports the results found from the hedonic regression analysis and provides some explanations for the patterns observed. Finally, Section 5 concludes. 


\section{Background and previous research}

In this section, we provide background information on the Irish broadband market and refer to previous applied research that uses hedonic valuation.

\subsection{The Irish broadband market}

In its quarterly report, ComReg (2011) outlines the composition of the fixed broadband market in Ireland. Figure 1 shows that in Q3 2011, Eircom's market share was 45.2\%, almost double the share of the next largest operator, UPC. Vodafone was the third largest operator in the fixed broadband market, in terms of subscriptions, with a share of $16.6 \%$. The remaining market was split between Digiweb, Imagine and other authorised operators (OAOs). All those operators with less than $2 \%$ of total fixed broadband subscriptions are grouped together under OAOs.

Figure 1 Fixed broadband market shares (subscriptions)

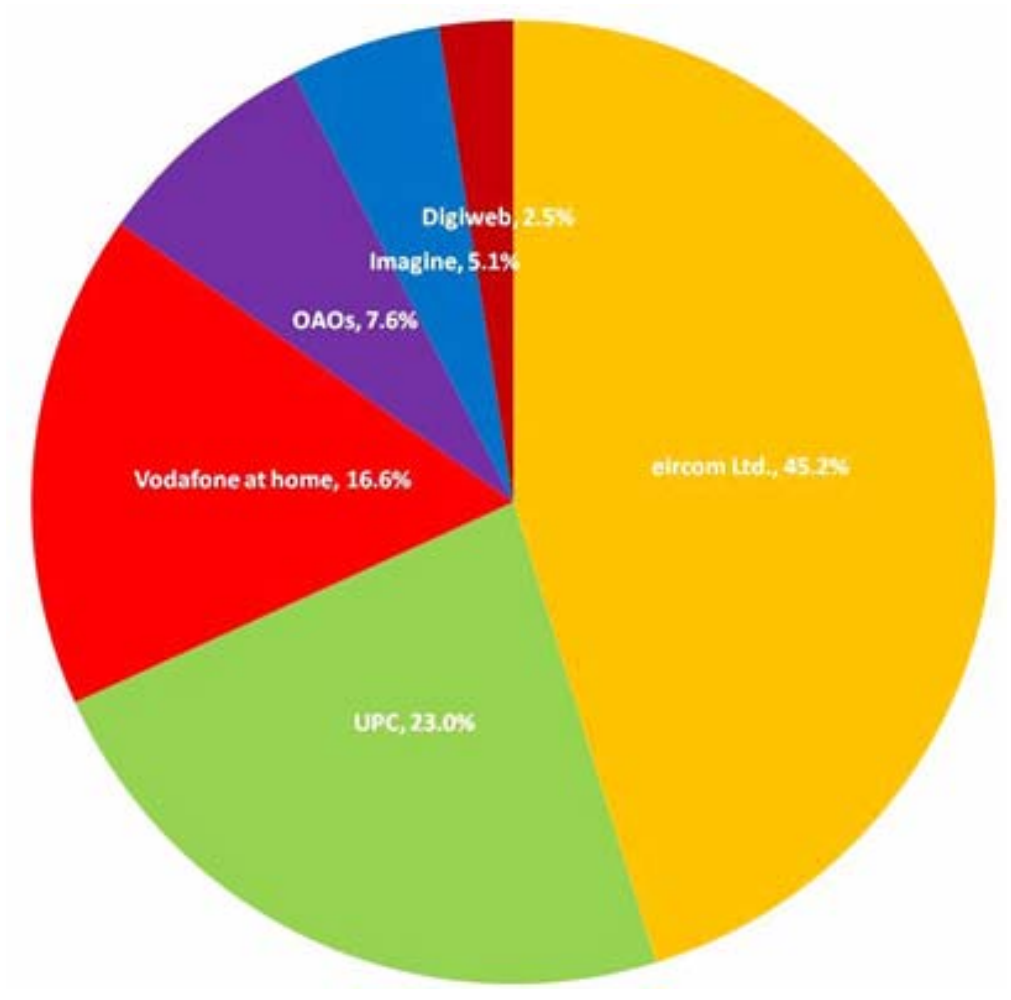

Source: ComReg (2011)

The report also shows that the mobile broadband market is split between four operators. O2, 3 and Vodafone share approximately $90 \%$ of the market, with Eircom providing the remaining $10 \%$.

According to ComReg, at the end of September 2011, there were 1,652,043 broadband subscriptions in Ireland. This represents a quarterly growth rate of $1.5 \%$ and a yearly growth rate of $6.7 \%$. Table 1 shows the levels and growth of the different methods 
of broadband provision in Ireland. Although DSL remains the largest access type in Ireland, its usage dropped from Q3 2010 to Q3 2011. Cable access experienced the largest yearly growth and the second largest quarterly growth, with mobile broadband also becoming increasingly popular.

Table 1 Broadband access type

\begin{tabular}{lccc}
\hline Platform & Q3'11 subs & $\begin{array}{c}\text { Quarterly growth } \\
\text { Q2'11-Q3'11 }\end{array}$ & $\begin{array}{c}\text { Year-on-year growth } \\
\text { Q3'10-Q3'11 }\end{array}$ \\
\hline DSL & 726,264 & $+0.3 \%$ & $-0.8 \%$ \\
Cable & 245,498 & $+7.4 \%$ & $+30.7 \%$ \\
Wireless & 76,959 & $-1.7 \%$ & $-2.4 \%$ \\
Other 20 & 10,114 & $+12.7 \%$ & $+11.1 \%$ \\
Sub-total & $1,058,835$ & $+1.4 \%$ & $+5.0 \%$ \\
Mobile broadband & 593,208 & $+1.6 \%$ & $+9.7 \%$ \\
Total & $1,652,043$ & $+1.5 \%$ & $+6.7 \%$ \\
\hline
\end{tabular}

Source: ComReg (2011)

\subsection{Hedonic regressions}

The hedonic regression model attempts to value components of a good or service. Although the hedonic approach can be traced as far back as Haas (1922), ${ }_{1}^{1}$ modern hedonic regression work is based on work by Griliches (1961) and Rosen (1974), which developed value indices for manufactured products that combined measures of quantity and quality. The seminal paper by Griliches (1961) developed a hedonic price index for automobiles. The central assumption in hedonic modelling is that goods are valued for their utility-bearing attributes and that these attributes are internalised into the price of the good.

The hedonic regression model has been used in a number of communications-related settings. Wallsten and Riso (2010) examined the relationship between broadband plan components and consumer prices in 30 different countries. Using hedonic regressions, they find that bitcaps can significantly reduce the price of broadband for consumers, provided they do not exceed the cap. Their results suggest that, in the case of standalone broadband, for example, each gigabyte of the cap is associated with an additional \$1.67 per year, with an additional premium for triple-play packages.

Stranger and Greenstein $(2007,2008)$ use hedonic regressions to examine pricing indexes in internet service providers (ISPs) during the 1990s. They find that new firms enter the market at a small but significant price discount to established incumbents, while the introduction of new products and technologies are priced at a significant price premium to the existing offerings. Similarly, Crocioni and Correa (2011) apply hedonic regressions to the broadband market in Ireland and the Netherlands to assess if firms have market power in the provision of differentiated services. Their results suggest that DSL providers in both countries have some degree of pricing power.

Hedonic regressions have been applied to goods markets with links to electronic communications, e.g., the electronic goods market (Berndt and Griliches 1993; Berndt and Rappaport, 2001). The hedonic regression model used in this paper is detailed in the next section. 


\section{Data employed}

\subsection{Data description}

Callcosts.ie is an interactive website provided by Ireland's Commission for Communications Regulation (ComReg) to help consumers compare the cost of personal mobile, home phone and broadband price plans. Authorised operators that provide mobile, home phone or broadband services are entitled to present tariff plans on the Callcosts.ie website.

In this paper, we construct a dataset from the information provided by providers of broadband and bundled services on Callcosts.ie. An individual observation exists in the dataset for each month that a broadband plan is on Callcosts.ie. If a plan was on offer for six months, for example, this would give rise to six observations in the dataset. A weighting variable is created to take account of plans that were only on offer for part of a month. When a plan is no longer offered by an operator, it is deactivated on the website but remains in an archive. Every plan recorded on Callcosts.ie since February 2006 is therefore part of our dataset, even if the plan is no longer available to customers.

From February 2006 to April 2011, 743 plans from 19 operators $^{2}$ were recorded on Callcosts.ie, resulting in 7,165 plan-month observations in the dataset. As well as the price of the plans, information is provided on a wide range of components of each plan. The main variables used in the analysis are described in Section 3.2 below. Information is also available on the cost of calls, billing options, frequency of billing, connection fees, county-level availability of each plan, and a wide range of other details of the plans. The county-level availability data is slightly different to the rest of the data, as it is only available for the date on which the data was extracted from the website. ${ }^{3}$ Analysis of the Irish broadband market over time must therefore take place at national level, while regional variation within the market can only be examined as of the 13th April 2011.

Broadband plans that are offered as part of a bundle with home phone services for one overall price are also included in the dataset. A binary variable, bundled, indicates if a plan is part of a bundle. Plans flagged as bundles will be those with both telephony and broadband services included together, for a combined price. However, before such bundles became common, we understand that operators often recommended separately priced home phone and broadband packages be purchased together. On Callcosts.ie, operators would link together a home phone plan with a suitable broadband plan that the operator also offered, but provide separate prices for each plan. These plans are not 'real' bundles and so are not considered to be a bundle in our analysis. Approximately one-third of plans in the dataset are part of a bundle.

Although the dataset contains a large number of plans, a selection bias may exist within the data as it was not mandatory for operators to list their plans on Callcosts.ie during the data period. A result of the optional nature of Callcosts.ie may be that only certain operators used the website, or operators only listed a certain type of plan on the website. Table 2 shows that of the top ten operators in terms of subscriptions in the fixed and mobile broadband markets, only the two with the lowest subscriber bases are not represented on Callcosts.ie. According to ComReg (2011) the operators represented on Callcosts.ie hold over $93 \%$ of fixed broadband subscriptions and $100 \%$ of mobile broadband subscriptions. 
Table 2 Top 10 fixed and mobile broadband operators in terms of subscriptions

\begin{tabular}{lc}
\hline Operators & Represented on Callcosts.ie \\
\hline Eircom & $\checkmark$ \\
Vodafone & $\checkmark$ \\
UPC & $\checkmark$ \\
3 Ireland & $\checkmark$ \\
O2 & $\checkmark$ \\
Imagine & $\checkmark$ \\
Digiweb & $\checkmark$ \\
Magnet Networks Ltd. & $\checkmark$ \\
Pure Telecom & $\times$ \\
Ripplecom Technologies Ltd. & $\times$ \\
\hline
\end{tabular}

Note: Meteor and eMobile are included with Eircom.

Source: Correspondence with ComReg

\subsection{Empirical estimation}

Using this data, we apply a simple hedonic approach to value components of the broadband service in Ireland. The hedonic regression used to estimate the value of each component can be written as:

$$
p=f(X, \beta)+u,
$$

where $p=\left(p_{1}, \ldots p_{M}\right)$ is a vector of the price observations and $X$ is an $(M \times K)$ matrix of the components vectors. The vector $\beta=\left(\beta_{0}, \ldots \beta_{K}\right)$ ' is a parameter vector that will be estimated through OLS. More specifically, the hedonic regression we estimate is:

$$
\begin{aligned}
& \text { Price }_{i t}=f\left(\text { download speed }_{i t}, \text { upload }_{\text {speed }} \text {, } \text { contention ratio }_{i t}\right. \text {, } \\
& \text { e-mail, } \text { unlimited }_{i t}, \text { access type }_{i t} \text {, } \text { contract }_{i t} \text {, }
\end{aligned}
$$

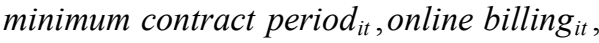

$$
\begin{aligned}
& \text { limited data transfer } \left.{ }_{i t} \text {, transfer limit }{ }_{i t}, \text { bundled }_{i t}, \phi_{i t}, \gamma_{i t}\right)
\end{aligned}
$$

where $\phi_{i t}$ and $\gamma_{i t}$ are time fixed effects and firm fixed effects respectively. These variables control for general trends or time-specific shocks, and factors specific to a firm that may affect the price. The other variables in the equation are explained below.

\subsubsection{Price}

The dependent variable in the model is the monthly price of a broadband plan. Due to the complex nature of pricing broadband services, we construct two separate dependent variables. The first price variable takes account of the advertised monthly fee, and recurring fees such as line rental and cable fees, if applicable. These fees are recurring monthly fees, and represent the fees that must be paid for the duration of the broadband service. 
The second price variable also includes once-off payments such as connection fees and modem fees. In the case where a minimum contract period applies with the plan, the once-off fee is divided by the number of months that a consumer must sign up to the plan. Where no contract exists with the plan the fee is divided by 12. Although this modification may overstate the true cost of the once-off fees for those who retain the broadband service for longer than the minimum contract period (or understate the costs for those with no contract that will change their broadband service sooner than 12 months time) it is a necessary step to ensure they are comparable to the recurring monthly fees.

Another element of the price of a broadband plan is the promotional rate offered by operators. Operators can enter promotional data on Callcosts.ie and link the promotion to plans they have entered previously. Promotions include reduced monthly fees for a specified number of months, reduced or waived connection fees, and extra download speed. Although these promotions could be included in the analysis, there are also a number of promotions that would be more difficult to include, such as free holiday vouchers and promotions conditional upon purchase of the plan online.

A more fundamental problem also exists with the promotions data. Despite having detailed information on each promotion, it is unclear which promotions were available with which plans. We are therefore unable to accurately include the promotions data in the analysis. For these reasons, the results in the paper are based on the full price, and do not include any promotional discounts.

\subsubsection{Download speed and upload speed}

The download speed variable represents the download speed of each plan, as advertised by the service provider. The use of the advertised download speed may not fully reflect the download speed available to each consumer. For example, in a study of UK broadband speeds, Ofcom (2009) found that the average headline speed offered by broadband providers was $7.1 \mathrm{Mbps}$, yet the average actual speed experienced by consumers was just 4.1 Mbps. Ofcom suggests that the difference between the advertised and actual speeds is a result of a number of constraints, such as the length of copper wire for DSL broadband, poor wiring, high contention ratios and consumer equipment performance. Despite these concerns, the advertised download speed is the best data available for a study of the Irish broadband market. Similarly, the upload speed variable represents the upload speed advertised by the operator. In the hedonic regression, we would expect these variables to have positive coefficients, indicating that the higher the download or upload speed offered with the plan, the higher the price will be.

\subsubsection{Contention ratio}

The contention ratio is a measure of the volume of users that can share bandwidth at any time. According to Ofcom, for all broadband connections, speeds are constrained by contention in the ISP's own network; this is a particular problem during peak periods as multiple users put demand on backhaul networks. Lower contention ratios, therefore, tend to be better for the consumer, so we would expect to see a negative coefficient on this variable. 


\subsubsection{E-mail unlimited}

This binary variable indicates if there are an unlimited number of e-mail accounts provided with the broadband plan. An unlimited number of e-mail accounts should increase the price of the plan, which suggests there should be a positive coefficient on the e-mail unlimited variable.

\subsubsection{Access type}

Five broadband access types are included in the dataset. Table 3 shows the share of each access type over the data period.

Table 3 Bundled plans

\begin{tabular}{lcc}
\hline Access type & Frequency & Percentage \\
\hline Cable & 789 & 11 \\
Datacard & 549 & 7.7 \\
Digital subscriber line (DSL) & 4,443 & 62 \\
Fibre to the home (FTTH) & 93 & 1.3 \\
Wireless & 1,291 & 18 \\
Total & 7,165 & 100.0 \\
\hline
\end{tabular}

Note: Data weighted by Mthdays (see Table 5).

Plans using satellite access was also included in the Callcosts.ie data, but because satellite services are normally much more expensive than other options we removed these plans to prevent them from giving rise to outliers in the analysis. The sign of the coefficient in the hedonic regression on each access type is dependent on the omitted category. Figure 2 suggests that fibre-to-the-home is most expensive, with DSL access second most expensive. Datacard access is the least expensive. The ranking of the other options depends on which price variable is used.

Figure 2 Median price for each broadband access type (see online version for colours)

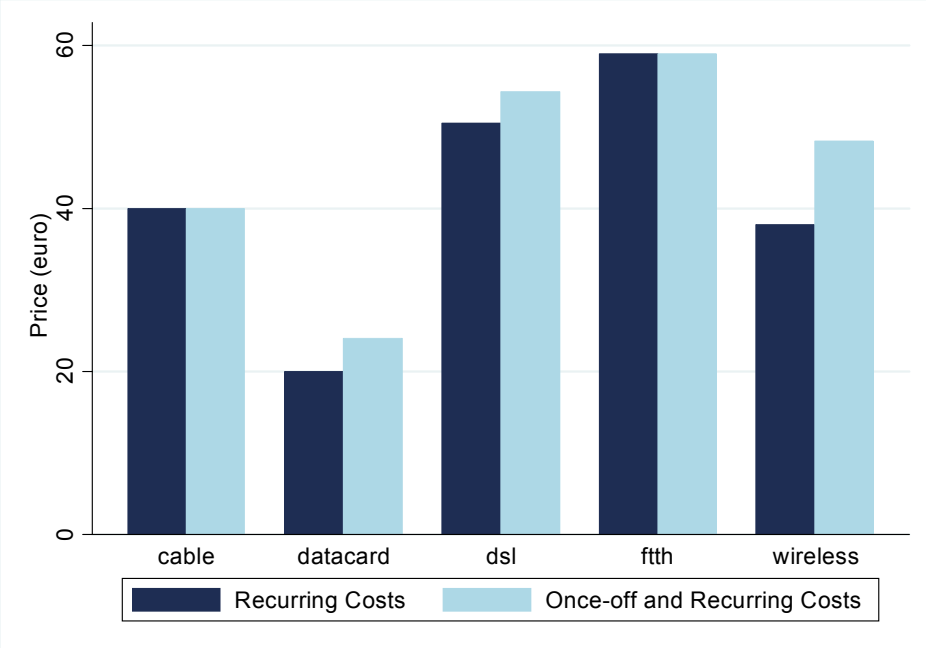




\subsubsection{Contract and minimum contract period}

The contract binary variable indicates if the plan has a contract. The minimum contract period variable, which is only active if the plan has a contract, indicates the minimum number of months that a consumer must sign up to the plan. Wallsten and Riso suggest that longer contracts reduce the monthly price for the consumer, although the effect is insignificant for bundles. The presence of a contract, they find, has no significant effect on the price. We would expect to see similar results here.

\subsubsection{Limited data transfer and transfer limit}

Some plans include a data transfer limit, above which additional costs are imposed on the consumer. The binary variable, limited data transfer, indicates if such a transfer limit exists in a plan. The transfer limit variable indicates the size of the limit in gigabytes (Gb). Data transfer limits are also known as bandwidth caps, or bitcaps. A data transfer limit would be expected to reduce the price of the plan.

\subsubsection{Bundled}

As previously discussed, the bundled variable indicates if a home phone service is included with the broadband plan for one price. A significant negative coefficient on this variable would suggest that operators offer a discount for purchasing more than one service together. A significant positive coefficient may suggest that consumers pay a premium for purchasing services together. Alternatively, a positive coefficient could be driven by a positively-valued characteristic that is omitted from the dataset but which is correlated with purchasing a bundle.

\subsubsection{Online billing}

This binary variable indicates if online billing is available with the plan. It seems unlikely that the availability of online billing would significantly change the price of a broadband package. A significant coefficient on this variable, therefore, may suggest that some other factor affecting the price of broadband is associated with plans offering online billing.

Table 4 Summary statistics

\begin{tabular}{lcccc}
\hline Variable & Mean & Min & Max & Std. dev. \\
\hline Price $(€)$ - recurring only & 47 & 8 & 170 & 18.3 \\
Price $(€)$ - once-off and recurring & 51.3 & 10.4 & 170 & 19.8 \\
Download speed (Mbps) & 5.4 & 0.5 & 105 & 6.5 \\
Upload speed (Mbps) & 0.8 & 0.1 & 8.4 & 1.4 \\
Contention ratio & 28 & 0 & 48 & 20 \\
Transfer limit $(\mathrm{Gb})$ & 31.6 & 1 & 300 & 40.2 \\
Minimum contract period (months) & 10.9 & 0 & 18 & 2.7 \\
\hline
\end{tabular}

Note: Data weighted by Mthdays (see Table 5).

In addition to the variables taken directly from Callcosts.ie, a number of variables were generated from the data. Table 5 describes these variables. 
Table 5 Generated variables

\begin{tabular}{ll}
\hline Variable & Description \\
\hline Price & $\begin{array}{l}\text { Dependent variable in the hedonic regressions. Includes advertised monthly } \\
\text { fee, line rental, cable fees, connection fees and modem fees in two different } \\
\text { specifications. }\end{array}$ \\
Mthdays & $\begin{array}{l}\text { Indicates the number of days in a month that the plan was on offer. Acts as a } \\
\text { weight in hedonic regressions. }\end{array}$ \\
GrOperator & $\begin{array}{l}\text { Groups operators together that are owned by the same company. } \\
\text { Downloadcat }\end{array}$ \\
DLmth & $\begin{array}{l}\text { Categorical specification of the download speed variable. } \\
\text { Download speed * time interaction term. }\end{array}$ \\
\hline
\end{tabular}

\section{Results}

\subsection{Patterns in the Irish broadband market over time}

Significant development took place in the broadband market in Ireland over the 2006 to 2011 period. The number of broadband packages available to the consumer increased dramatically, as did the variation of services within broadband packages. Using the Callcosts.ie data, we highlight a number of areas in which broadband services changed significantly in the 2006 to 2011 period.

Figure 3 illustrates the increase in the number of plans recorded on Callcosts.ie since February 2006. For every plan recorded in the data in mid-2006, there were approximately 15 plans recorded by early 2010 . However, it is not clear how much of this growth was due to listing of existing plans on Callcosts.ie and how much related to new plans.

Figure 3 Number of plans available on Callcosts.ie (see online version for colours)

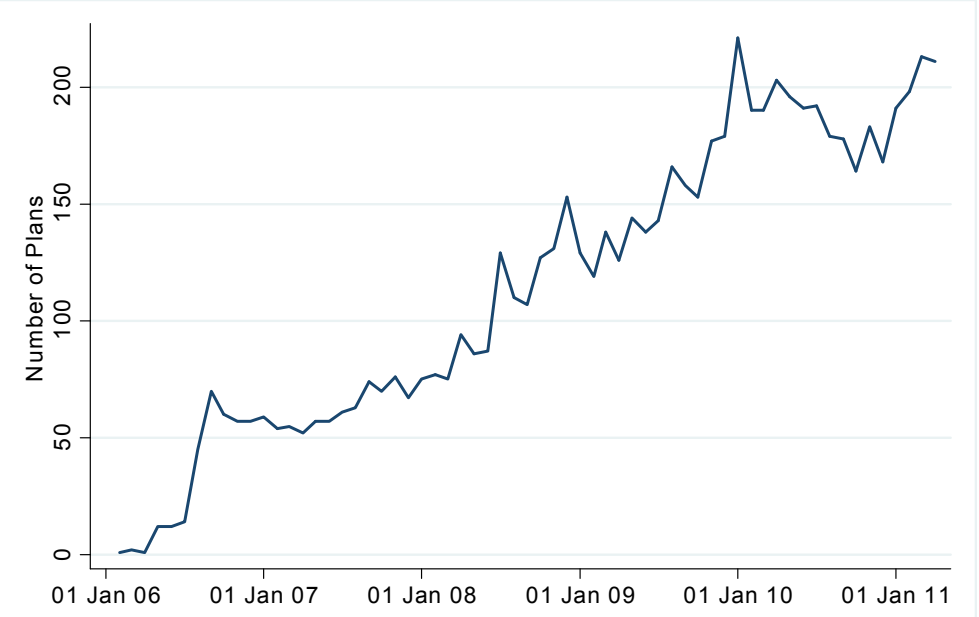


In early 2007, the median download speed in broadband packages was just above 2 Mbps. By April 2011, the median download speed had increased to almost 7.5 Mbps. This represents an increase of over $250 \%$ in just over four years. Figure 4 illustrates this relationship.

Figure 4 Median download speed (see online version for colours)

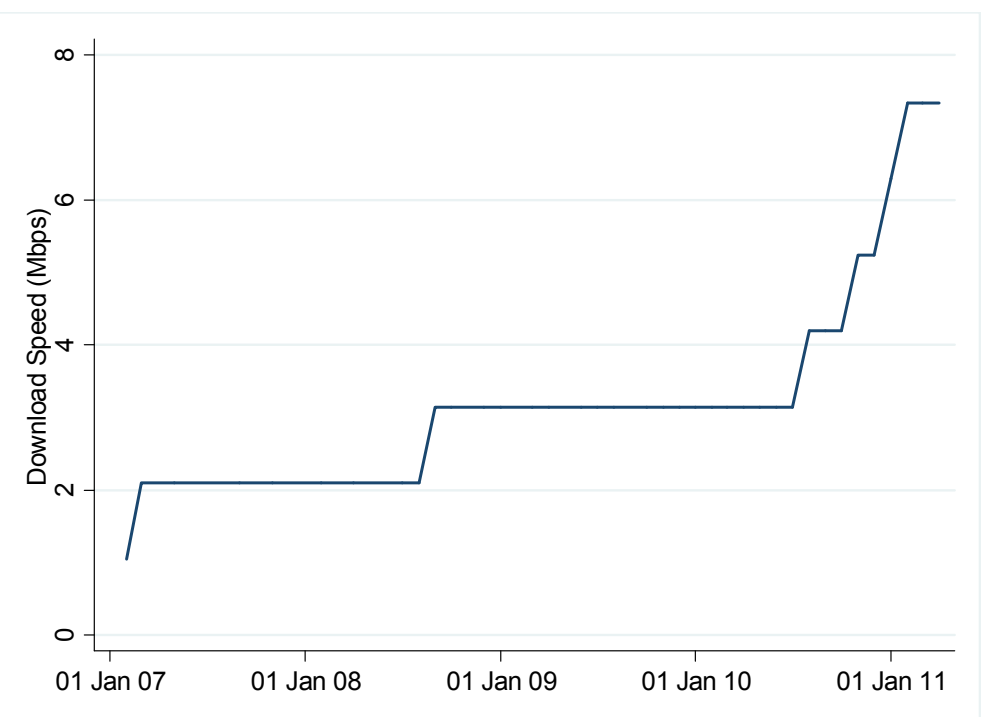

The increase in median download speed can be seen as a combination of improved download speeds in existing broadband access types, and the introduction of new technology into the market. Over half of the increase in median download speed came since mid-2010 when, among other factors, a number of high-speed cable and FTTH packages became available.

Figure 5 shows that the increase in the median download speed was small compared to the increase in the maximum download speed available in Ireland over the same time period. In April 2011, broadband packages offered download speeds up to $104 \mathrm{Mbps}$, compared to a maximum download speed just above $3 \mathrm{Mbps}$ in early 2007. It must be noted that Chorus are the only operator in the data offering $104 \mathrm{Mbps}$ download speed; the next highest download speed available is $52 \mathrm{Mbps}$.

Not only have download speeds increased over the time period under consideration, but other measures of quality also indicate an improvement in broadband packages. The contention ratio, for example, is a measure of the volume of users that can share bandwidth at any time. Therefore, all else equal, lower contention ratios should be associated with a higher quality connection. Since early 2007, the median contention ratio has more than halved, falling from 48 to 20, again reflecting an improvement in existing technology and the introduction of new technologies. Mobile broadband and FTTH broadband, for example, only offer uncontested broadband. 
Figure 5 Maximum, minimum and median download speed

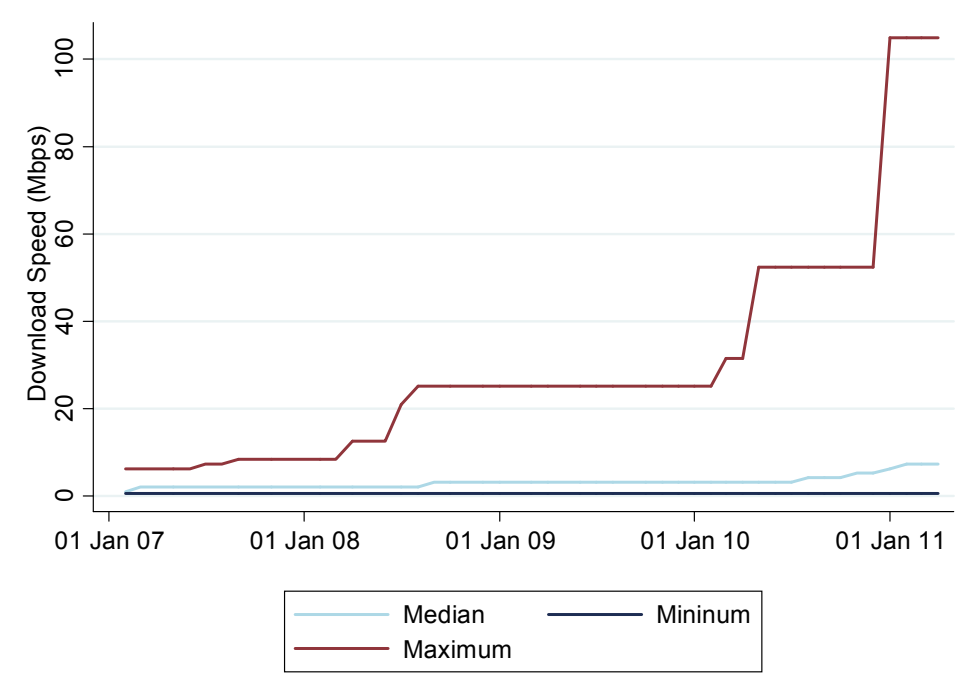

Figure 6 Median fixed fee per month

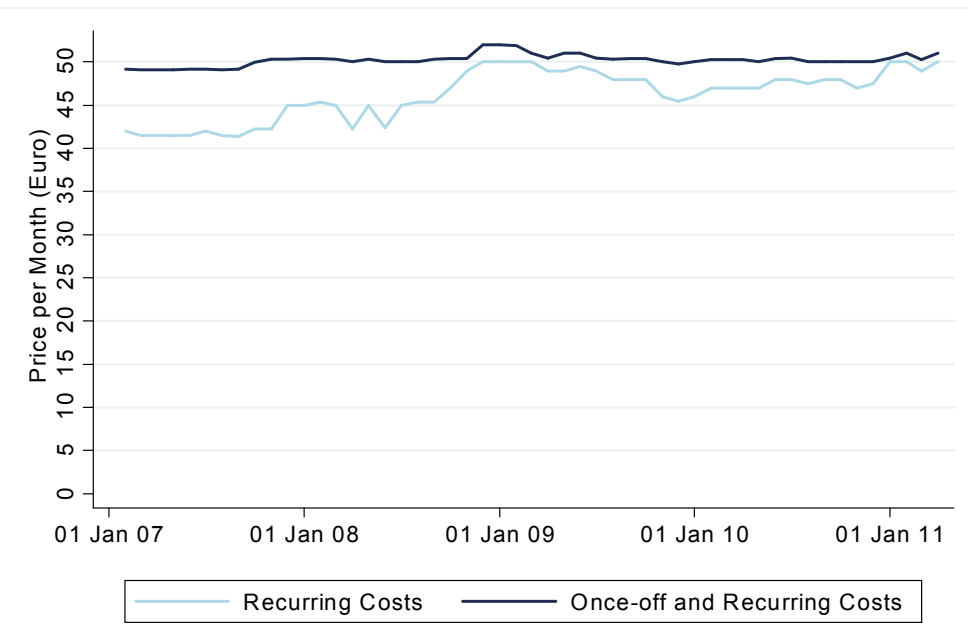

With sizeable improvements in download speeds and contention ratios, it would be reasonable to expect that the price of broadband packages also significantly increased over the data period. Figure 6 illustrates changes in the nominal median monthly price of a broadband package. Examining recurring costs only, the monthly fee has gradually increased since the beginning of 2007. A slight increase in the median price occurs from the middle of 2008 , when the fee increased from varying below $€ 45$ to varying below $€ 50$, driven mainly by the introduction of an Irish Broadband plan costing $€ 170$ a month. However, when once-off fees are taken into account, the median price of broadband packages remains remarkably stable. This indicates that once-off fees have become a less 
significant part of the overall price of broadband packages, with the two lines close to converging towards the end of the data period. Any decreases experienced in the once-off fees, therefore, have been offset by an increase in the monthly recurring fees.

\subsection{Regional variation in the Irish broadband market}

In addition to changes over time in the broadband market in Ireland, we can also test for regional variation in the Irish market. Figure 7 shows that there is some degree of price variation across counties in Ireland. The two biggest cities, Dublin and Cork, have the lowest median monthly fixed fee, with consumers in other cities such as Limerick and Kilkenny also facing relatively low prices. Consumers in less densely populated counties, such as Leitrim, Roscommon and Offaly, face relatively high monthly fees for broadband. However, the difference between the highest price and lowest price counties is relatively small, at approximately $€ 2$ per month.

Figure 7 Median fixed monthly fee across counties (see online version for colours)

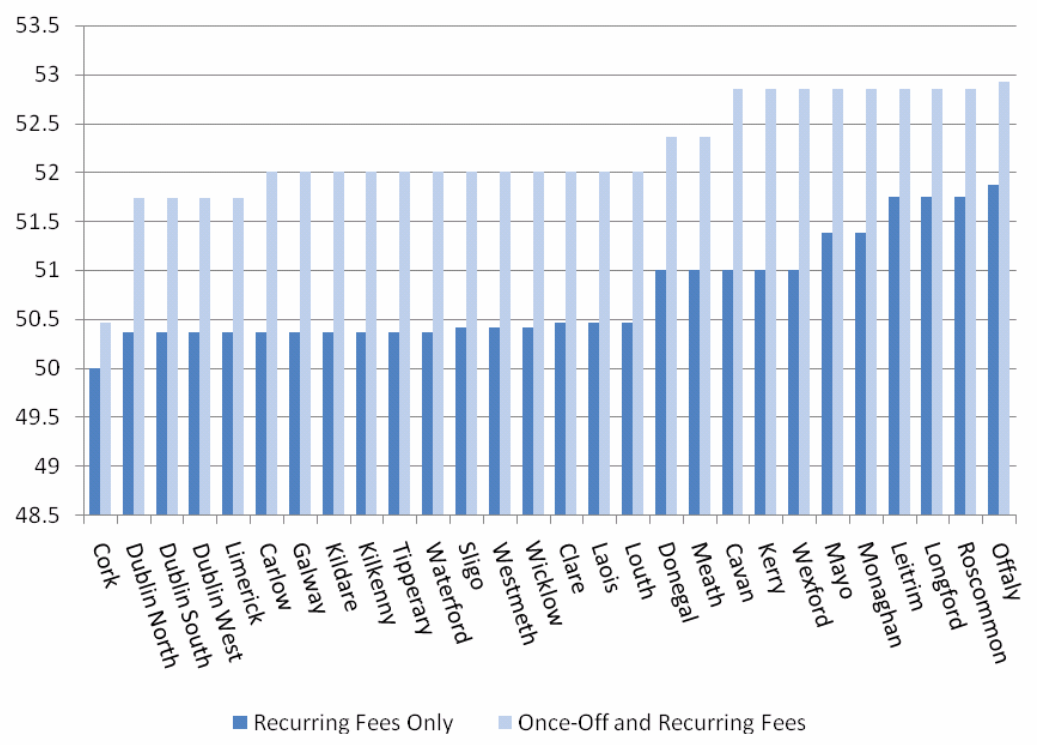

This pattern is reflected in the number of operators providing broadband in different counties. Although there are almost 20 different operators in the Callcosts.ie data, some of these operators are owned or have been taken over by other operators. ${ }^{4}$ For this reason, Figure 8 also shows the number of 'grouped' operators in each county, where a 'grouped' operator is any of the operators owned by the same company. Under both measures, the pattern is very similar. Remote areas of Ireland, such as Cavan, Kerry and Roscommon have the fewest number of operators providing broadband. The cities, on the other hand, have the highest number of operators. However the difference between the numbers of operators in any two counties is small, with only three additional 'grouped' operators present in the Cork compared to Cavan, for example. 
Figure 8 Number of operators across counties (see online version for colours)

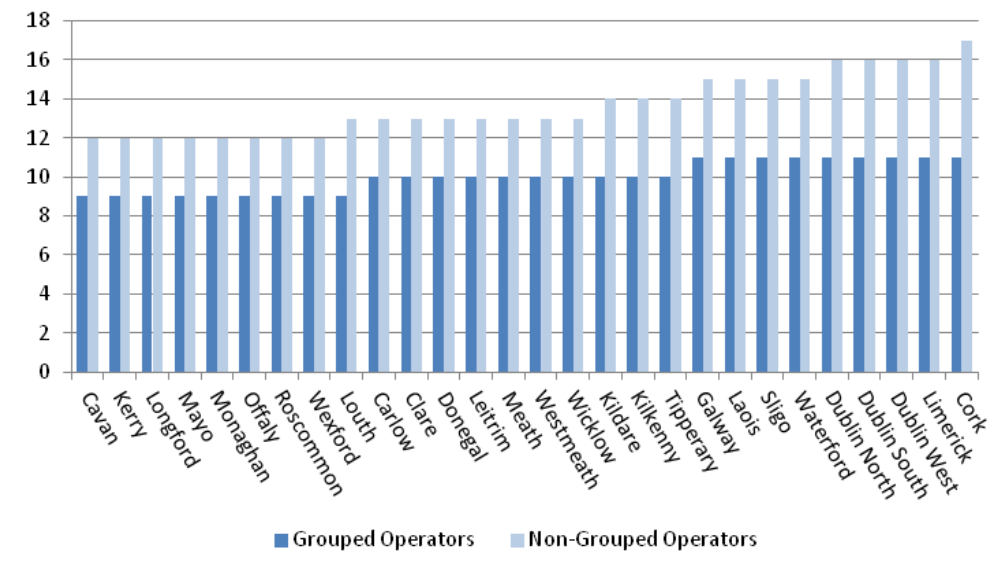

Finally, the median advertised download speed is also higher in the cities and lower in the remote counties, although there are a number of exceptions to this. Kilkenny is in the lower bracket of median download speed, with remote counties such as Sligo and Cavan facing median download speeds equivalent to those in Cork and Dublin. It must be borne in mind that these are the advertised 'up to' download speeds, and not the actual download speed experienced by the consumer.

Figure 9 Median download speed across counties (see online version for colours)

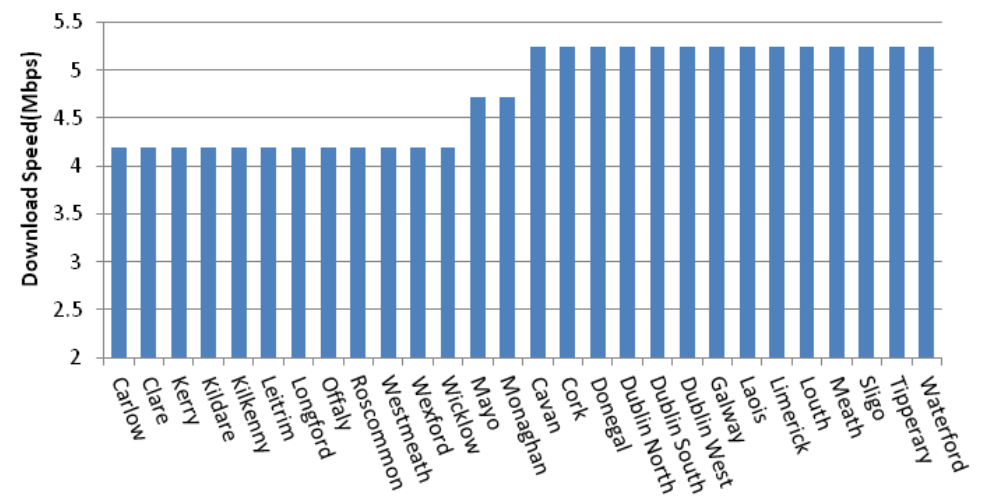

Although variation does exist in broadband packages, in terms of price and quality, across counties in Ireland, the degree of variation between the largest cities and the more rural counties is quite small. This may be due to the nature of the Callcosts.ie data. As the data is only available at the county level, we are likely to be observing broadband availability in the largest towns in each county. Intra-county variation is not identified in the data, so consumers in rural areas of each county may not have access to each (or any) of the broadband packages in the data. 
The hedonic regressions reported in the next section of the paper attempt to disaggregate the different price components of broadband plans by estimating the value of each service element in a broadband package.

\subsection{Hedonic regression}

The results of the hedonic regression are presented in Table 6. Overall, a clear pattern emerges for many of the explanatory variables. The cost of a broadband plan increases as the download and upload speeds increase, while lower contention ratio also increase the price. Contracts do not seem to affect the price of plans significantly. The results are discussed in more detail below.

The results for four separate regressions are shown in Table 6. The first two regressions include only the recurring fees in the dependent variable, while the last two regressions include both recurring and once-off fees. Regressions 1 and 3 do not include an interaction term. In these regressions we can interpret the coefficients on the download variable as the average marginal effect on price over the whole period studied. Models 3 and 4 include a download and time interaction term. This allows us to estimate the change in the valuation of download speed over time. However, including the interaction term means that the download speed coefficients can no longer be interpreted as the average marginal effect. ${ }^{5}$

Table 6 Hedonic regression results

\begin{tabular}{ccccc}
\hline & $(1)$ & $(2)$ & $(3)$ & $(4)$ \\
\hline $\begin{array}{l}\text { Median of dependent variable (price) } \\
\text { Download speed: }\end{array}$ & $\epsilon 47$ & $\epsilon 47$ & $\epsilon 50.36$ & $\epsilon 50.36$ \\
$2 \mathrm{Mb}-5 \mathrm{Mb}$ & & & & \\
& $\left(0.570^{* * *}\right.$ & $12.40^{* * *}$ & $5.987^{* * *}$ & $11.88^{* * * *}$ \\
$5 \mathrm{Mb}-10 \mathrm{Mb}$ & $12.01^{* * *}$ & $23.17^{* * *}$ & $8.657^{* * *}$ & $22.27^{* * *}$ \\
& $(0.529)$ & $(1.205)$ & $(0.623)$ & $(1.418)$ \\
$10 \mathrm{Mb}-50 \mathrm{Mb}$ & $30.29^{* * *}$ & $48.21^{* * *}$ & $26.41^{* * *}$ & $48.27^{* * *}$ \\
& $(0.658)$ & $(1.859)$ & $(0.775)$ & $(2.189)$ \\
$>50 \mathrm{Mb}$ & $44.14^{* * *}$ & $71.15^{* * *}$ & $42.77^{* * *}$ & $75.73^{* * *}$ \\
& $(3.093)$ & $(4.039)$ & $(3.644)$ & $(4.755)$ \\
Download * Month & - & $-0.134^{* * *}$ & - & $-0.164 * * *$ \\
& - & $(0.0130)$ & - & $(0.0153)$ \\
Upload speed (Mb) & $2.125^{* * *}$ & $2.019^{* * * *}$ & $1.837^{* * *}$ & $1.707^{* * *}$ \\
& $(0.170)$ & $(0.169)$ & $(0.201)$ & $(0.199)$ \\
Contention ratio & $-0.211^{* * *}$ & $-0.216^{* * *}$ & $-0.293^{* * *}$ & $-0.298^{* * *}$ \\
& $(0.0141)$ & $(0.0140)$ & $(0.0167)$ & $(0.0165)$ \\
\hline
\end{tabular}

Notes: Standard errors in parentheses.

$* * * p<0.01, * * p<0.05, * p<0.1$

0 to $2 \mathrm{Mb}$ and cable access type omitted.

Firm and time fixed effects not shown here.

(1) and (2) recurring fees only, (3) and (4) recurring and once-off fees 
Table 6 Hedonic regression results (continued)

\begin{tabular}{|c|c|c|c|c|}
\hline & (1) & (2) & (3) & (4) \\
\hline \multicolumn{5}{|l|}{ Access type: } \\
\hline Datacard & $\begin{array}{c}-31.12^{* * *} \\
(2.228)\end{array}$ & $\begin{array}{c}-31.05 * * * \\
(2.211)\end{array}$ & $\begin{array}{c}-35.72 * * * \\
(2.624)\end{array}$ & $\begin{array}{c}-35.64 * * * \\
(2.603)\end{array}$ \\
\hline DSL & $\begin{array}{c}6.112 * * * \\
(1.604)\end{array}$ & $\begin{array}{c}5.924 * * * \\
(1.592)\end{array}$ & $\begin{array}{l}3.753 * * \\
(1.890)\end{array}$ & $\begin{array}{l}3.523 * \\
(1.875)\end{array}$ \\
\hline Ftth & $\begin{array}{c}-7.979 * * * \\
(2.473)\end{array}$ & $\begin{array}{c}-7.338 * * * \\
(2.455)\end{array}$ & $\begin{array}{c}-21.83 * * * \\
(2.913)\end{array}$ & $\begin{array}{c}-21.05 * * * \\
(2.890)\end{array}$ \\
\hline Wireless & $\begin{array}{c}-9.921 * * * \\
(1.535)\end{array}$ & $\begin{array}{c}-9.968 * * * \\
(1.524)\end{array}$ & $\begin{array}{c}-3.677 * * \\
(1.808)\end{array}$ & $\begin{array}{c}-3.735 * * \\
(1.794)\end{array}$ \\
\hline Contract & $\begin{array}{l}0.0514 \\
(2.163)\end{array}$ & $\begin{array}{l}-0.373 \\
(2.148)\end{array}$ & $\begin{array}{c}0.367 \\
(2.548)\end{array}$ & $\begin{array}{l}-0.151 \\
(2.528)\end{array}$ \\
\hline Minimum contract period & $\begin{array}{l}0.182 * * \\
(0.0917)\end{array}$ & $\begin{array}{l}0.194 * * \\
(0.0910)\end{array}$ & $\begin{array}{c}0.00563 \\
(0.108)\end{array}$ & $\begin{array}{l}0.0194 \\
(0.107)\end{array}$ \\
\hline Unlimited data transfer & $\begin{array}{c}0.174 \\
(0.658)\end{array}$ & $\begin{array}{l}-0.170 \\
(0.654)\end{array}$ & $\begin{array}{c}-2.755^{* * *} \\
(0.775)\end{array}$ & $\begin{array}{c}-3.175^{* * *} \\
(0.770)\end{array}$ \\
\hline Data transfer limit $(\mathrm{Gb})$ & $\begin{array}{l}-0.00668 \\
(0.00588)\end{array}$ & $\begin{array}{c}0.00302 \\
(0.00592)\end{array}$ & $\begin{array}{c}0.0207 * * * \\
(0.00693)\end{array}$ & $\begin{array}{c}0.0325 * * * \\
(0.00697)\end{array}$ \\
\hline Bundle & $\begin{array}{c}6.191 * * * \\
(1.105)\end{array}$ & $\begin{array}{c}6.571 * * * \\
(1.098)\end{array}$ & $\begin{array}{c}4.281 * * * \\
(1.302)\end{array}$ & $\begin{array}{c}4.744 * * * \\
(1.292)\end{array}$ \\
\hline Unlimited e-mail & $\begin{array}{c}10.75^{* * *} \\
(1.301)\end{array}$ & $\begin{array}{c}10.08^{* * *} \\
(1.293)\end{array}$ & $\begin{array}{c}7.039 * * * \\
(1.532)\end{array}$ & $\begin{array}{c}6.223^{* * *} \\
(1.522)\end{array}$ \\
\hline Online billing & $\begin{array}{c}-2.290 * * \\
(1.103)\end{array}$ & $\begin{array}{c}-2.923 * * * \\
(1.097)\end{array}$ & $\begin{array}{c}-3.990 * * * \\
(1.299)\end{array}$ & $\begin{array}{c}-4.763 * * * \\
(1.291)\end{array}$ \\
\hline Observations & 7,146 & 7146 & 7,146 & 7146 \\
\hline R-squared & 0.608 & 0.614 & 0.534 & 0.542 \\
\hline
\end{tabular}

Notes: Standard errors in parentheses.

${ }^{* * *} p<0.01, * * p<0.05,{ }^{*} p<0.1$

$0-2 \mathrm{Mb}$ and cable access type omitted.

Firm and time fixed effects not shown here.

and (2) Recurring Fees only, (3) and (4) Recurring and Once-Off Fees

\subsection{Discussion}

\subsubsection{Download speed and upload speed}

The results indicate that the monthly price of a broadband plan increases as the download speed and upload speed increase. In all models, the 0 to $2 \mathrm{Mb}$ download speed is the omitted category. To change from a plan with download speed between 0 and $2 \mathrm{Mb}$ to a $2 \mathrm{Mb}$ to $5 \mathrm{Mb}$ plan would cost approximately $€ 6$ to $€ 7.50$ extra a month. Moving to a plan with download speeds between $5 \mathrm{Mb}$ and $10 \mathrm{Mb}$ costs approximately $€ 8.50$ to $€ 12$ extra, while to change to a plan with download speeds above $10 \mathrm{Mb}$ would cost $€ 26$ or more. 
A similar pattern emerges with the upload speed variable (which we treat as linear), although at a lower cost per $\mathrm{Mb}$. Each extra $\mathrm{Mb}$ of upload speed costs approximately $€ 2$ extra per month. The download speed and upload speed coefficients are all significant at the $1 \%$ significance level.

The download speed and time interaction term in regressions 3 and 4 are negative and highly significant. This suggests that the cost per $\mathrm{Mb} / \mathrm{s}$ of download speed is decreasing over time. A supply side explanation is most likely. With the introduction of better technologies in the industry, the cost of supplying an extra Mbps of download speed is reduced. The download and time interaction term is likely to be reflecting this pattern.

When we plot the marginal valuation of an extra Mbps of download speed, an interesting pattern emerges. As expected, we observe a downward relationship, indicating that the value of an extra Mbps of download speed is lower at higher download speeds. In the simple specification we use, the marginal valuation even becomes negative at the highest download speeds. The strong negative relationship shown here may reflect a diminishing marginal cost of supplying broadband speed; or, on the assumption that broadband market is in equilibrium and is competitive, it could indicate that the marginal willingness-to-pay for high speed broadband falls to zero once a certain level of broadband speed is reached. The level and trend of consumers' willingness to pay for high speed services requires further research, because it is an important input to models of service viability and the potential cost of universal service programmes.

Figure 10 Implied marginal valuation per $\mathrm{Mb} / \mathrm{s}$ download speed (see online version for colours)

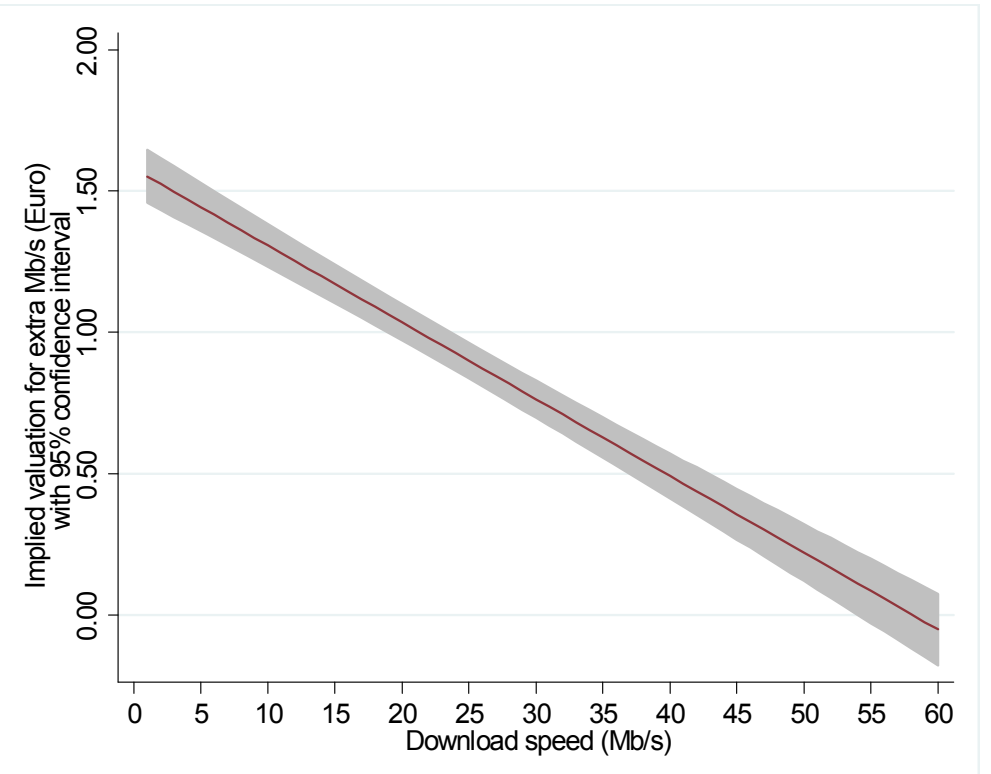

\subsubsection{Contention ratio and access type}

Higher contention ratios are less expensive than lower contention ratios. The results suggest that reducing the contention ratio by one increases the price by between $21 \mathrm{c}$ and 29 c a month. In practice it is unlikely that consumers would experience such small 
changes in their contention ratios. It may be more helpful to think of reduction in contention ratio from 48 to one increasing the monthly price of a plan by between $€ 10$ and $€ 14$

DSL is the most expensive access type ${ }^{6}{ }^{6}$ although the difference between cable and DSL is insignificant when the once-off fees are included in the model. Similarly, the difference between wireless and cable broadband turns insignificant when once-off fees are included, as wireless access tends to incur high connection fees. Mobile broadband is the cheapest access type, possibly reflecting reliability concerns that are not controlled for in the model. Surprisingly, FTTH broadband has a highly significant negative coefficient, suggesting that it is the second cheapest access type. This result could be due to operators offering subsidised 'market-entry' prices to consumers, as the FTTH technology only entered the market during 2010.

\subsubsection{Contract variables}

Neither the contract indicator variable nor the minimum contract period variable is statistically significant at the $1 \%$ significance level under either specification of the dependent variable. This suggests that on average customers do not receive a lower a price by committing to a plan for a certain period of time.

\subsubsection{Data transfer limit variables}

Without including once-off fees, data transfer limits seem to have no effect on the monthly price of a plan. However, when we include once-off fees in the dependent variable, we find a negative coefficient on the data transfer limit variable, suggesting that plans with limited data transfer are about $€ 3$ cheaper than those that do not impose limits. Unsurprisingly, the larger the limit the more expensive is the plan, although only by an extra $2 \mathrm{c}$ to $3 \mathrm{c}$ per $\mathrm{Gb}$. A plan with a data transfer limit of $100 \mathrm{~Gb}$ to $150 \mathrm{~Gb}$ would therefore, all else equal, cost the same as an unlimited plan.

\subsubsection{Bundle, unlimited e-mail and online billing variables}

The bundle variable controls for the price difference between standalone broadband plans and broadband plans packaged with a home phone or television service. As expected, this variable is positive and statistically significant.

The unlimited e-mail and online billing coefficients are harder to explain. Although it is not impossible that unlimited e-mail accounts in a plan increases the price by between $€ 6$ and $€ 10$ a month, we believe that the variable may be correlated with some other unobserved aspect of quality of a plan, and this explains part of the effect we are finding.

Similarly, as discussed in Section 3, the significance of the online billing variable suggests that there are determinants of the price omitted from the model that are biasing the coefficient downwards. Indeed, the availability of online billing is most prevalent in plans with high contention ratios and low download speeds; the negative coefficient on the online billing variable suggests that there is some other factor associated with these plans that is negatively correlated with the price. 


\section{Conclusions}

Using data from Callcosts.ie, ComReg's broadband price comparison website, this paper highlights the growth in the quality and quantity of broadband plans available to consumers in Ireland. By April 2011, the median download speed offered to consumers increased to almost 7.5 Mbps, while the maximum speed available grew to $107 \mathrm{Mbps}$. Uncontended broadband also become more prevalent with improvements in technology. The choice available to consumers also grew significantly, with the number of different plans available to consumers rising above 200 during 2010 and 2011. The median nominal monthly price for broadband plans remained remarkably constant throughout the data period, particularly when once-off fees are included. Despite some concerns about selection issues in the data, clear patterns emerge of widespread improvements in choice and quality for broadband consumers in Ireland.

The increased quality of services is not limited to the main cities in Ireland, with the number of plans, download speeds and price all relatively comparable across counties in Ireland. However the county-level data undoubtedly hides significant intra-county variation in broadband availability, particularly in more rural areas of Ireland.

The paper also estimated the partial values associated with various components of broadband service. Higher download speeds, higher upload speeds and lower contention ratios were all associated with higher prices. Similarly, data transfer limits reduce the price, while contracts seem to have no significant effect on the price for consumers.

We found strong evidence that the marginal valuation of an extra Mbps download speed is negative. Indeed, with our simple specification of the speed-price relationship, incremental speed has a negative value at speeds above $60 \mathrm{Mbps}$. Of course, it is unlikely that the value of speed ever actually becomes negative, but it is plausible that the marginal cost of supplying speed falls to a very low level as speed increases due to the technologies employed to provide such services or there is minimal demand for services with very high download speeds. Further, study is required in this area and would be greatly helped by the availability of demand-side data.

Since the 1st July 2011, ComReg's powers to provide an interactive tariff guide became stronger, and we understand that they can now require that operators provide details of all broadband plans. If this is implemented, it should help improve the representativeness of the Callcosts.ie data and remove any concerns about selection bias. If data on the demand for each plan were to become available in future, this would allow further inferences to be drawn about the market.

\section{Acknowledgements}

This research was funded by the ESRI Programme of Research in Communications, with contributions from Ireland's Department for Communications, Energy and Natural Resources and the Commission for ComReg. We are grateful to comments on an earlier draft from Pete Lunn and participants at an ESRI seminar, the 2012 Applied Econometrics and Public Policy Conference at NUI Galway and the 2012 Irish Society of New Economists Conference. The usual disclaimer applies. 


\section{References}

Berndt, E.R. and Griliches, Z. (1993) 'Price indexes for microcomputers: an exploratory study', in Foss, M., Manser, M. and Young, A. (Eds.): Price measurements and their uses, Studies in Income and Wealth, Vol. 57, pp.63-93, University of Chicago Press, Chicago.

Berndt, E.R. and Rappaport, N.J. (2001) 'Price and quality of desktop and mobile personal computers: a quarter century historical overview', American Economic Review, Vol. 91, No. 2, pp.268-273.

Brambor, T., Clark, W.R. and Golder, M. (2006) 'Understanding interaction models: improving empirical analyses', Political Analysis, Vol. 14, pp.63-82.

Colwell, P.F. and Dilmore, G. (1999) 'Who was first? An examination of an early hedonic study', Land Economics, Vol. 75, No. 4, pp.620-626.

ComReg (2010) Strategy Statement 2010-2012, Document 10/47, ComReg, Dublin [online] $\mathrm{http}: / /$ www.comreg.ie/publications/comreg_s_strategy_statement_2010_2012.539.103643. p.html (accessed 10 September 2012).

ComReg (2011) Irish Communications Market: Key Data Report-Q3 2011, Document 11/98, ComReg, Dublin [online] http://www.comreg.ie/_fileupload/publications/ComReg1198.pdf.

Crocioni, P. and Correa, L. (2012) 'Can evidence of pricing power help market power assessment? Broadband internet in Ireland and the Netherlands', Telecommunications Policy, Vol. 36, No. 5, pp.419-433.

Department of Communications, Marine and Natural Resources (DCENR) (2012) Enabling a Connected Society: Report of the Next Generation Broadband Taskforce, May [online] http://www.dcenr.gov.ie/NR/rdonlyres/1AE24C27-40AD-4A73-879F4536250C87BC/0/FullReport.pdf (accessed 2 May 2012).

Forfás (2010) Ireland's Broadband Performance and Policy Actions, Forfás, Dublin [online] $\mathrm{http} / /$ www.forfas.ie/media/forfas100122-Broadband-Benchmarking-Ireland.pdf (accessed 4 March 2013).

Griliches, Z. (1961) 'Hedonic price indices for automobiles', in Griliches, Z. (Ed.): Price Indices and Quality Change: Studies in New Methods of Measurement, Harvard University Press, Cambridge.

Haas, G.C. (1922) 'Sale prices as a basis for farm land appraisal', Technical Bulletin 9, The University of Minnesota Agricultural Experiment Station, St. Paul.

Howell, B. and Grimes A. (2010) 'Productivity questions for public sector fast fibre network financiers', Communications \& Strategies, 2nd quarter, Vol. 78, pp.127-145.

Kenny, R and Kenny, C. (2011) 'Superfast broadband: is it really worth a subsidy?', Info, Vol. 13, No. 4, pp.3-29.

Ofcom (2009) UK Broadband Speeds 2009, Consumers' Experience of Fixed-Line Broadband Performance, Research Report, 28 July, Ofcom, London [online] $\mathrm{http}$ //stakeholders.ofcom.org.uk/binaries/research/telecoms-research/broadbandspeeds.pdf (accessed 10 September 2012).

Rosen, S. (1974) 'Hedonic prices and implicit markets: product differentiation in pure competition', Journal of Political Economy, January/February, Vol. 82, No. 1, pp.34-55.

Stranger, G. and Greenstein, S. (2007) 'Pricing at the on-ramp to the internet: price indexes for ISPs during the 1990s', in Berndt, E. and Hulten, C. (Eds.): Hard to Measure Goods and Service: Essays in Memory of Zvi Griliches, University of Chicago Press, Chicago.

Stranger, G. and Greenstein, S. (2008) 'Pricing in the shadow of firm turnover: ISPs during the 1990s', International Journal of Industrial Organization, Vol. 26, No. 3, pp.625-642.

Wallsten, S.J. and Riso, J. (2010) Residential and Business Broadband Prices Part 1: An Empirical Analysis of Metering and Other Price Determinants, Technology Policy Institute Working paper. 


\section{Notes}

1 See Colwell and Dilmore (1999) for a full discussion of the history of hedonic regressions.

2 Although 19 different operators are recorded on Callcosts.ie, some of these are owned by the same company or changed name during the data period.

3 13th April 2011.

4 For example, Perlico is owned by Vodafone, and Irish Broadband is owned by Imagine.

5 See Brambor et al. (2006) for details.

6 Recall that satellite plans are dropped from the analysis. 